\title{
Review \\ New horizons and perspectives in the treatment of osteoarthritis
}

\author{
Francis Berenbaum
}

Pierre \& Marie Curie Paris 6 University, Department of Rheumatology, APHP Saint-Antoine Hospital, 184 rue du faubourg Saint-Antoine, 75012 Paris, France

Corresponding author: Francis Berenbaum, francis.berenbaum@sat.aphp.fr

Published: 17 October 2008

This article is online at http://arthritis-research.com/supplements/10/S2/S1

(c) 2008 BioMed Central Ltd

Arthritis Research \& Therapy 2008, 10(Suppl 2):S1 (doi:10.1186/ar2462)

\begin{abstract}
Osteoarthritis (OA) is increasingly prevalent worldwide and is associated with a significant economic burden. Despite the increasing number of patients with $\mathrm{OA}$, treatments to manage the condition remain symptomatic, designed to control pain, and improve function and quality of life while limiting adverse events. Both the EULAR (European League Against Rheumatism) and the OARSI (Osteoarthritis Research Society International) issued new guidelines in 2007 and 2008 recommending a combination of nonpharmacological and pharmacological modalities to manage $\mathrm{OA}$ effectively. Because of gastrointestinal risks (including ulcer complications) and cardiovascular risks (including hypertension and thrombotic events associated with nonsteroidal anti-inflammatory drugs [NSAIDs]), these guidelines propose acetaminophen as the first choice anti-inflammatory agents. However, NSAIDs are considered to be more effective than acetaminophen for relief of pain. Given the efficacy, safety, and tolerability issues associated with NSAIDs, development of new agents to manage the pain associated with arthritis but without the cardiovascular and gastrointestinal adverse events remains a priority. This review considers current recommendations for the treatment of $\mathrm{OA}$, the most recent evidence on the cardiovascular risks associated with current NSAID treatments, and the potential of newer antiinflammatory agents with improved benefit-risk profiles.
\end{abstract}

\section{Introduction}

Osteoarthritis $(O A)$ is becoming increasingly prevalent worldwide because of the combination of an aging population and growing levels of obesity. A study reported in 2005 [1] indicated that OA affected $9.6 \%$ of men and $18 \%$ of women aged 60 years or older, or a total of 26 million individuals. Although age is the strongest predictor of the development of $\mathrm{OA}$, obesity, trauma, and physically demanding occupations and activities also increase the risk for OA of the hand, knee, and hip $[2,3]$. Because the most powerful predictor of OA development and progression is increasing age, it is expected that more individuals will develop the disease, making it even more essential that effective strategies to manage the pain and disability associated with $\mathrm{OA}$ are developed. Along with the current armamentarium of available therapies, development of new agents with potentially improved safety profiles may offer new alternatives for these patients.

\section{Burden of osteoarthritis Functional burden}

OA imposes a significant functional burden on affected individuals. NHANES III (the Third National Health and Nutrition Examination Study) revealed that more than $8 \%$ of US adults have symptomatic hand $\mathrm{OA}$, and there were no sex-specific differences [4]. Furthermore, these individuals had difficulty lifting 10 pounds, dressing and eating, and had significantly increased use of analgesics, particularly acetaminophen. There was no increase in the use of nonsteroidal antiinflammatory drugs (NSAIDs). A French study [5] found that more than $80 \%$ of clinical OA patients reported limitations in their daily lives, including basic tasks, work and leisure activities, and these limitations affected patients who were retired as well as those still working. Finally, Heuts and coworkers [6] measured the association between pain-related fear and daily living in patients with $\mathrm{OA}$ and found that pain levels and fear of (re)injury were both associated with significant functional limitations. Interestingly, radiological findings were not significant predictors as compared with pain-related fear, emphasizing the need for effective analgesics that can be used in the long term.

\section{Economic burden}

OA imposes a significant economic burden for both patients and health-care systems. Rabenda and colleagues [7] measured the direct and indirect costs to individuals with $O A$. The mean direct cost to patients was $€ 44.5$ per patientmonth, and this included hospitalizations, drugs, and physician examinations. In addition, patients also required a mean 0.8 days sick leave per patient-month, resulting in substantial costs to employers, whereas unaffected care givers required an average 0.2 days sick leave per patient-month. $A$

$\mathrm{AHA}=$ American Heart Association; CINOD = cyclo-oxygenase inhibiting nitric oxide donator; COX = cyclo-oxygenase; EULAR = European League Against Rheumatism; NSAID = nonsteroidal anti-inflammatory drug; OA = osteoarthritis; OARSI = Osteoarthritis Research Society International. 
study conducted in the USA [8] revealed that patients with OA incur direct costs of more than $\$ 2,600$ per year, approximately twice as much as do individuals without OA. Similarly, a Canadian study [9] confirmed that $60 \%$ of patients experienced costs directly related to their $O A$ and that much of this was due to time lost from work and leisure activities for patients and unpaid care givers.

Health care systems also bear an economic burden due to OA. A study [10] calculated that from July 1993 to June 1994, the annual cost to an individual health maintenance organization for 10,101 patients with OA was more than $\$ 4.7$ million, including hospital care, medications, and ambulatory care. The authors pointed out that the OA care was infrequent and that the largest portion of the expenditure was for hospitalizations, which affected only $5 \%$ of the OA patients; this indicates that there is a need for improved OA management. A French study [11] calculated that in 2002 the direct costs of $\mathrm{OA}$ in France were $€ 1.6$ billion, which comprised about $1.7 \%$ of expenditure for the French health care system. Expenditures in 2002 were 156\% higher than in 1993, primarily due to an increased number of patients. These numbers also reinforce the need for effective strategies to manage the symptoms of OA and decrease the number of patients with functional disability.

\section{Treatment recommendations \\ Summary of guidelines}

As the number of individuals with $O A$ increases, effective strategies to manage the pain and disability of OA will become even more important. Guidelines for the management of OA have been published recently by both the OsteoArthritis Research Society International (OARSI) [12,13] and the European League Against Rheumatism (EULAR) [14-16]. Experts from multiple disciplines, who analyzed and weighed the scientific and clinical evidence as well as previous guidelines, developed recommendations for the management of knee, hip, and hand OA. The guidelines indicate that a combination of pharmacological and nonpharmacological modalities is the most effective strategy to manage the pain and disability associated with $\mathrm{OA}$.

Pharmacological guidelines for the management of OA recommend acetaminophen up to $4 \mathrm{~g} /$ day as first-line therapy and suggest that alternative pharmacological therapy should be used only in the presence of an inadequate response and severe pain [13-15]. This is because of a perceived lower risk for adverse events from acetaminophen as compared with NSAIDs. Both OARSI and EULAR guidelines recommend a switch to NSAIDs if acetaminophen cannot adequately control symptoms or if there are signs of clinical inflammation (Table 1) [13]. Once the decision has been made to use NSAIDs, OARSI and EULAR guidelines both recommend the lowest effective dose and, in patients with increased gastrointestinal risk, consideration of a gastroprotective agent such as proton pump inhibitors or misoprostol. All of the guidelines recommend monitoring of individual patients after initiation of NSAID treatment. Finally, the OARSI and EULAR guidelines recommend that if patients do not respond to oral analgesics, then they should receive intra-articular injections of either corticosteroids or hyaluronate for OA of the knee or hip, followed by the use of opioids and narcotics only when all other pharmacological options have been considered. Surgery, including joint replacement, is recommended only as a last resort.

Despite the recommendation that acetaminophen be used as first-line therapy, there is evidence that NSAIDs may be more effective than acetaminophen for the control of pain in patients with OA. Several published studies have suggested that acetaminophen is not as effective as either NSAIDs $[17,18]$ or placebo [19]. In addition, a systematic review conducted by the US Agency for Healthcare Research and Quality [20] indicated that although there does not appear to be efficacy differences between selective and nonselective NSAIDs, all NSAIDs appear to be superior to both acetaminophen and placebo for the treatment of OA symptoms. Although the recent EULAR and OARSI guidelines recognize differences in efficacy, the recommendations for initial treatment with acetaminophen remain based on issues of safety [13-15].

\section{American Heart Association recommendations for the use of nonsteroidal anti-inflammatory drugs}

The American Heart Association (AHA) recently issued a controversial statement that included a stepped care approach to the management of musculoskeletal symptoms [21]. The AHA recommends that for patients with symptoms that cannot be controlled by nonpharmacological approaches, acetaminophen, full doses of aspirin, nonacetylated salicylates, or short-term narcotics should be used as initial therapy, and only those individuals who cannot tolerate the previous treatments or who require long-term or high-dose therapy should receive NSAIDs. Nonselective NSAIDs should be used first, and only if symptoms are not controlled should NSAIDs with 'increasing degrees of COX-2 [cyclooxygenase-2] inhibitory activity' be used before 'ultimately concluding with the COX-2 selective NSAIDs.' The AHA rationale for this approach is that some COX-2 selective NSAIDs might carry increased risk for cardiovascular events compared with nonselective NSAIDs.

Concerns about the AHA recommendations were addressed in an editorial published in 2007 [22]. First, Moskowitz and coworkers [22] wrote that nonacetylated salicylates tend to be less effective than NSAIDs and may take longer to benefit patients. There is also no evidence to support the contention that nonacetylated salicylates have an improved cardiovascular safety profile compared with NSAIDs. In addition, the authors of the editorial stated that full-dose aspirin confers increased risk for gastrointestinal bleeding as well as the potential for increased hemorrhagic stroke. The authors 
Table 1

OARSI pharmacological recommendations for the management of knee and/or hip OA

Recommendation

Strength of recommendation

$(\%)(95 \% \mathrm{Cl})$

Acetaminophen (up to $4 \mathrm{~g} /$ day) can be an effective initial oral analgesic for the treatment of mild to

$92(88-99)$

moderate pain in patients with knee or hip OA. In the absence of an adequate response, or in the presence

of severe pain and/or inflammation, alternative pharmacologic therapy should be considered based on relative

efficacy and safety, as well as concomitant medications and co-morbidities.

In patients with symptomatic hip or knee OA, NSAIDs should be used at the lowest effective dose but their long-term use should be avoided if possible. In patients with increased gastrointestinal risk, either a COX-2 selective agent or a nonselective NSAID with co-prescription of a PPI or misoprostol for gastroprotection may be considered, but NSAIDs, including both nonselective and COX-2 selective agents, should be used with caution in patients with cardiovascular risk factors.

Reprinted from Zhang et al. [13] with permission from Elsevier. COX, cyclo-oxygenase; NSAID, nonsteroidal anti-inflammatory drug; OA, osteoarthritis; OARSI, Osteoarthritis Research Society International; PPI, proton pump inhibitor.

suggested that the AHA reconsider their recommendations. Finally, because there is no clinical support for the idea that it is possible to differentiate cardiovascular risk among selective and nonselective NSAIDs on the basis of in vitro COX-2/ COX-1 inhibition ratios, the editorial suggested that COX-2 selective agents should be considered, particularly in patients with increased gastrointestinal risk, although NSAID drugs should only be prescribed after evaluation of the risk/benefit balance for the individual patient [22].

Moskowitz and coworkers [22] also disagreed with the AHA regarding the early use of opioids to treat patients with musculoskeletal pain, arguing that long-term use is not recommended by either the American Pain Society or the American Academy of Pain Management. In addition, the editorial points out that patients with OA tend to be older and therefore more likely to experience adverse events associated with opioid use; these include dizziness, confusion, and risk for falling, which could in turn increase the risk for hip fracture.

\section{Benefit/risk profile of nonselective and cyclo-oxygenase-2 inhibiting nonsteroidal anti-inflammatory drugs Cardiovascular risk}

A number of studies have been conducted to determine the cardiovascular risks associated with both selective and nonselective NSAIDs. An epidemiological study conducted by McGettigan and Henry [23] identified increased risk for cardiovascular events with rofecoxib, whereas HernandezDiaz and colleagues [24] observed increased risk with rofecoxib and diclofenac, and presented data suggesting an increase in risk for cardiovascular events with ibuprofen. In their meta-analysis, Kearney and coworkers [25] reported that the COX-2 selective NSAIDs rofecoxib and celecoxib, as well as high doses of the nonselective NSAIDs ibuprofen and diclofenac, were all associated with moderately increased risk for cardiovascular events. In contrast, high-dose naproxen was not associated with increased vascular risk. The authors went on to state that there was insufficient data to determine whether naproxen is protective, as has been suggested in other studies.

Although the meta-analysis reported by Kearney and coworkers was unable to determine whether cardiovascular risk differed between aspirin users and nonusers, Strand [26] discussed epidemiological studies reporting that concomitant aspirin therapy decreases the risk for cardiovascular events with COX-2 inhibitors as well as some nonselective NSAIDs, but not with ibuprofen [27,28]. That investigator also indicated that these events were confirmed in the CLASS (Celecoxib Long-term Arthritis Safety Study) [29] and TARGET (Therapeutic Arthritis Research and Gastrointestinal Event Trial) [30] trials.

In addition to an increase in the risk for cardiovascular events, NSAIDs increase blood pressure. Two meta-analyses [31,32] concluded that NSAIDs increase both systolic and diastolic blood pressures, and a later clinical trial [33] indicated that although treatment with rofecoxib significantly elevated 24hour systolic blood pressure, this was not the case in patients receiving celecoxib or naproxen. However, the authors noted that all three NSAIDs destabilized hypertension control, reiterating the need for careful monitoring of patients with hypertension.

\section{Gastrointestinal risks}

NSAIDs are also associated with gastrointestinal events, including dyspepsia and heartburn (which affect up to $60 \%$ of NSAID users), as well as gastric and duodenal ulcers [34]. Garcia Rodriguez and Hernandez-Diaz [35] found that the risk for symptomatic but uncomplicated peptic ulcer increased from 1.03 per 1,000 person-years in individuals who did not use NSAIDs or aspirin to 4.0 per 1,000 personyears for nonaspirin NSAID users. In addition, this risk increased slightly when patients used NSAIDs for more than 6 months. Furthermore, the use of aspirin either with or 
Table 2

\section{Clinicians guide to anti-inflammatory therapy}

\begin{tabular}{lll}
\hline & No or low gastrointestinal risk & NSAID gastrointestinal risk \\
\hline $\begin{array}{l}\text { No cardiovascular risk } \\
\text { (without aspirin) }\end{array}$ & Nonselective NSAID (cost consideration) & $\begin{array}{l}\text { COX-2 selective inhibitor } \\
\text { or } \\
\text { Nonselective NSAID + PPI } \\
\text { or } \\
\text { COX-2 selective inhibitor + PPI for patients with previous }\end{array}$ \\
$\begin{array}{ll}\text { Cardiovascular risk } \\
\text { (with aspirin) }\end{array}$ & $\begin{array}{l}\text { Naproxen } \\
\text { Addition of PPI if gastrointestinal risk of } \\
\text { aspirin/NSAID combination warrants } \\
\text { gastroprotection }\end{array}$ & $\begin{array}{l}\text { Add PPI irrespective of NSAID } \\
\text { COX-2 selective inhibitor + PPI for those with previous }\end{array}$ \\
gastrointestinal bleeding
\end{tabular}

${ }^{a}$ Contraindications to nonselective nonsteroidal anti-inflammatory drugs (NSAIDs) include heart failure and treatment of perioperative pain in the setting of coronary artery bypass surgery. Contraindications for selective cyclo-oxygenase (COX)- 2 inhibitors include established ischemic heart disease, cereberovascular disease, peripheral arterial disease, and treatment of perioperative pain within the setting of coronary artery bypass surgery. bNonselective or selective (low-dose) NSAID without established aspiring interaction if naproxen is ineffective. Data from Jones and coworkers [39]. PPI, proton pump inhibitor.

without other NSAIDs increased the risk for uncomplicated peptic ulcer. A systematic review of epidemiological studies [36] showed that the pooled relative risk for a complicated peptic ulcer was 3.8 for nonselective NSAID use, although the review did find some differences between specific NSAIDs. An observational study of elderly patients conducted to determine the risk for complicated gastrointestinal events in patients receiving NSAIDs [37] found that the incidence of complicated upper gastrointestinal bleeding with nonselective NSAIDs was 4.0, whereas the risk among those using celecoxib was 1.0. This illustrates that COX-2 selective inhibitors do decrease the risk for gastrointestinal complications.

A decreased risk for gastrointestinal events has also been observed in clinical trials. For example, the CLASS study [29] revealed that celecoxib users had fewer symptomatic ulcers and complications than did individuals who received therapeutic doses of nonselective NSAIDs, although the statistical significance was not reached at 1 year. In addition, the MEDAL (Multinational Etoricoxib and Diclofenac Arthritis Long-term) [38] study demonstrated that individuals who received etoricoxib had significantly fewer uncomplicated gastrointestinal events than those who received diclofenac. Patient risk factors that increase the risk for developing gastrointestinal side effects include age, a history of ulcer or dyspepsia, Helicobacter pylori status, and concurrent diseases (for review [39]).

The question of whether low-dose aspirin abrogates the gastrointestinal protection of COX-2 inhibitors is continuing to be addressed. Strand [26] argued that although evidence from the CLASS and TARGET studies does not show a significant benefit, the MEDAL study identified significantly fewer complicated ulcer events with etoricoxib and aspirin than with diclofenac and aspirin.

\section{Balancing cardiovascular and gastrointestinal risks of nonsteroidal anti-inflammatory drugs}

Moore and coworkers [40] calculated the absolute risk for cardiovascular and gastrointestinal events and determined that although gastrointestinal complications occur more frequently with nonselective NSAIDs than with selective COX-2 inhibitors, serious cardiovascular events occur at approximately equal rates. A retrospective cohort study examining administrative data from elderly patients who filled a prescription for NSAIDs or acetaminophen [41] showed that among patients who did not use aspirin, the risk for hospitalization for acute myocardial infarction/gastrointestinal bleeding was greater with naproxen, but the risk associated with celecoxib was comparable to that with acetaminophen. In aspirin users, both naproxen and celecoxib appeared to be the least toxic. Based on these data, Jones and colleagues [39] developed evidence-based recommendations according to the gastrointestinal risks and the cardiovascular risks at the individual level (Table 2).

\section{Renal risks}

Renal adverse events associated with NSAID use include decreased renal perfusion, edema, increased blood pressure, and interstitial nephritis $[42,43]$. Although these events are relatively rare, the number of patients receiving NSAIDs makes the risks clinically relevant, and patients at increased risk include those with age-related declines in glomerular filtration rate, those with hypovolemia, and those with congestive heart failure, cirrhosis, or nephrosis (for review [44]). Based on the adverse events associated with rofecoxib, it is possible that adverse events are attributable to a class effect. However, a meta-analysis performed to quantify the risks for renal events (including renal dysfunction, hypertension, and peripheral edema) associated with COX-2 inhibitors [45] found that although rofecoxib was associated with increased renal events, no increase was seen with other COX-2 selective NSAIDs. 


\section{Acetaminophen risks}

Despite published recommendations stating that acetaminophen has a better safety profile than NSAIDs $[13,15]$, recent reports have suggested that there are more adverse events associated with acetaminophen than was previously believed. For example, a UK nested case-control analysis including more than 950,000 individuals between 1993 and 1998 [46] showed that individuals who used more than $2 \mathrm{~g} /$ day acetaminophen had a relative risk of 3.6 for upper gastrointestinal complications versus relative risks of 2.4 and 4.9 for low/medium and high doses of NSAIDs, respectively. These findings were supported by other studies. One [47] found that among patients aged 65 years or older, those receiving higher doses of acetaminophen had an increased risk for gastrointestinal events compared with those receiving lower doses. Another [48] revealed that use of a combination of a nonselective NSAID plus acetaminophen may increase the risk compared with either agent alone. In addition, there are studies in the literature that suggest that acetaminophen use may be associated with a modest increase in risk for renal functional decline in women consuming more than $3 \mathrm{~g} /$ day [49] and that in patients with early-stage chronic renal failure acetaminophen use may exacerbate the effects of renal failure [50]. Furthermore, studies suggest that acetaminophen use is associated with a moderate increase in risk for incident hypertension in both men [51] and women [52]. Given these results, clinicians must consider the safest therapeutic agent for individual patients with OA.

\section{The cyclo-oxygenase inhibiting nitric oxide donating class}

Given the safety issues described above, there is a clear need to develop drugs that have the efficacy of NSAIDs but with an improved safety profile. Cyclo-oxygenase-inhibiting nitric oxide donating drugs (CINODs) may offer one alternative, and the potential ability of CINODs to ameliorate gastric damage due to NSAIDs is illustrated in Figure 1 [53]. These drugs are synthesized by linking a nitric oxide moiety to an NSAID via an ester linkage. They have been shown in laboratory and early clinical studies to be efficacious in the treatment of pain and inflammation, and they may help to reduce NSAID-induced gastric damage [2,54-56]. Naproxcinod was shown to induce significantly less gastric damage than the parent compound naproxen, while exhibiting equivalent analgesic and anti-inflammatory activities in an animal model [57]. Furthermore, clinical studies have demonstrated a trend toward lower blood pressure in patients receiving naproxcinod as compared with naproxen [58]. More research will help to determine whether CINODs are effective agents for the treatment of OA.

\section{Conclusion}

Based on the current recommendations, paracetamol/ acetaminophen should be the first line drug to be prescribed because of a safer profile compared with NSAIDS, even if its efficacy is not as clear on an evidence-based medicine
Figure 1

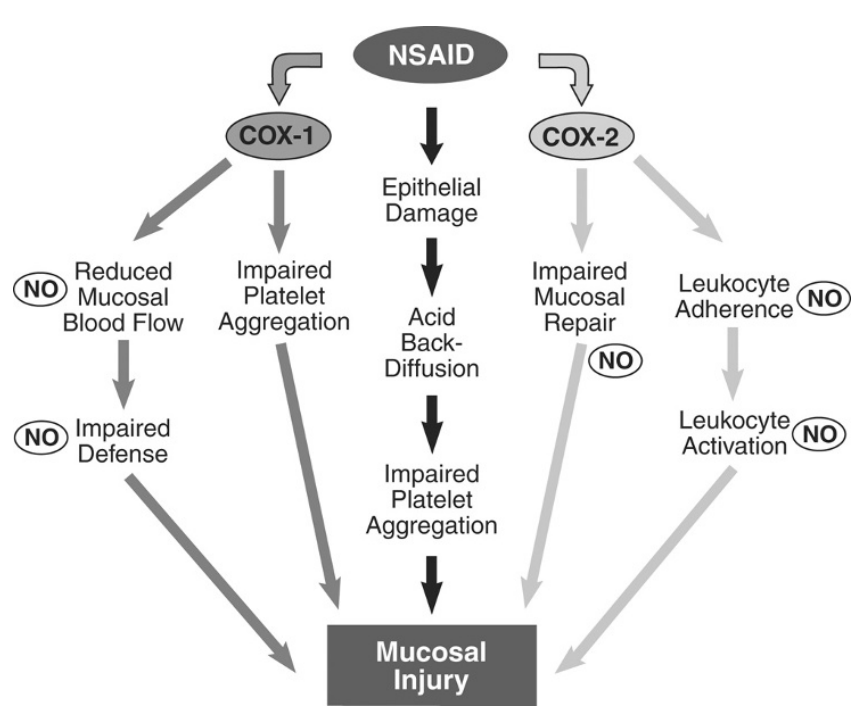

Therapeutic potential of exogenous nitric oxide (NO) in NSAID-induced gastric damage. Presented is a diagram of the pathogenesis of NSAIDinduced gastric mucosal injury and the possible steps at which exogenous NO could help to protect against NSAID-induced gastric damage. Reproduced with permission from Wallace [53]. COX, cyclooxygenase; NSAID, nonsteroidal anti-inflammatory drug.

approach. NSAIDS are the second line, although many adverse events may occur, some of them potentially serious. So, the objectives now are to find new ways to keep the efficacy of NSAIDS but with less serious side effects. The new subfamily of NSAIDs, called CINODs, could be of interest by limiting the NSAID-induced hypertension, a surrogate marker for NSAID-induced myocardial infarction. Clinical studies are ongoing in order to confirm this positive effect.

\section{Competing interests}

FB has consulted for, or received grants from Pfizer, NicOx, Combinatorx, Rottapharm, Expanscience, Pierre Fabre, Genevrier and Servier.

\section{Acknowledgments}

The author would like to thank Nina Leeds for editorial and referencing assistance with this manuscript.

This article is published as part of Arthritis Research \& Therapy Volume 10 Supplement 2, 2008: New insights in the role of nitric oxide in the management of osteoarthritis. The full contents of the supplement are available online at http://arthritis-research.com/supplements/10/S2.

Publication of the supplement has been supported by an unrestricted educational grant from $\mathrm{NicOx}$.

\section{References}

1. Woolf $A D$, Pfleger $B$ : Burden of major musculoskeletal conditions. Bull World Health Organ 2003, 81:646-656.

2. Lohmander LS, Englund PM, Dahl LL, Roos EM: The long-term consequence of anterior cruciate ligament and meniscus injuries: osteoarthritis. Am J Sports Med 2007, 35:1756-1769.

3. Lohmander LS, Gerhardsson M, Rollof J, Nilsson PM, Engstrom G: Incidence of severe knee and hip osteoarthritis in relation 
to different measures of body mass. A population-based prospective cohort study. Ann Rheum Dis 2008 [Epub ahead of print].

4. Dillon CF, Hirsch R, Rasch EK, Gu Q: Symptomatic hand osteoarthritis in the United States: prevalence and functional impairment estimates from the third U.S. National Health and Nutrition Examination Survey, 1991-1994. Am J Phys Med Rehabil 2007, 86:12-21.

5. Fautrel B, Hilliquin P, Rozenberg S, Allaert FA, Coste P, Leclerc A, Rossignol M: Impact of osteoarthritis: results of a nationwide survey of 10,000 patients consulting for OA. Joint Bone Spine 2005, 72:235-240.

6. Heuts PH, Vlaeyen JW, Roelofs J, de Bie RA, Aretz K, van Weel $\mathrm{C}$, van Schayck OC: Pain-related fear and daily functioning in patients with osteoarthritis. Pain 2004, 110:228-235.

7. Rabenda V, Manette C, Lemmens R, Mariani AM, Struvay N, Reginster JY: Direct and indirect costs attributable to osteoarthritis in active subjects. $J$ Rheumato/ 2006, 33:1152-1158.

8. Gabriel SE, Crowson CS, Campion ME, O'Fallon WM: Direct medical costs unique to people with arthritis. J Rheumatol 1997, 24:719-725.

9. Gupta S, Hawker GA, Laporte A, Croxford R, Coyte PC: The economic burden of disabling hip and knee osteoarthritis (OA) from the perspective of individuals living with this condition. Rheumatology (Oxford) 2005, 44:1531-1537.

10. Lanes SF, Lanza LL, Radensky PW, Yood RA, Meenan RF, Walker AM, Dreyer NA: Resource utilization and cost of care for rheumatoid arthritis and osteoarthritis in a managed care setting: the importance of drug and surgery costs. Arthritis Rheum 1997, 40:1475-1481.

11. Le Pen C, Reygrobellet C, Gerentes I: Financial cost of osteoarthritis in France. The 'COART' France study. Joint Bone Spine 2005, 72:567-570.

12. Zhang W, Moskowitz RW, Nuki G, Abramson S, Altman RD, Arden N, Bierma-Zeinstra S, Brandt KD, Croft P, Doherty M, Dougados M, Hochberg M, Hunter DJ, Kwoh K, Lohmander LS, Tugwell P: OARSI recommendations for the management of hip and knee osteoarthritis, part I: critical appraisal of existing treatment guidelines and systematic review of current research evidence. Osteoarthritis Cartilage 2007, 15:981-1000.

13. Zhang W, Moskowitz RW, Nuki G, Abramson S, Altman RD, Arden N, Bierma-Zeinstra S, Brandt KD, Croft P, Doherty M, Dougados M, Hochberg M, Hunter DJ, Kwoh K, Lohmander LS, Tugwell P: OARSI recommendations for the management of hip and knee osteoarthritis, Part II: OARSI evidence-based, expert consensus guidelines. Osteoarthritis Cartilage 2008, 16: 137-162.

14. Zhang W, Doherty M, Arden N, Bannwarth B, Bijlsma J, Gunther $\mathrm{KP}$, Hauselmann HJ, Herrero-Beaumont G, Jordan K, Kaklamanis $\mathrm{P}$, Leeb B, Lequesne M, Lohmander S, Mazieres B Martin-Mola $\mathrm{E}$, Pavelka K, Pendleton A, Punzi L, Swoboda B, Varatojo R, Verbruggen G, Zimmermann-Gorska I, Dougados M; EULAR Standing Committee for International Clinical Studies Including Therapeutics (ESCISIT): EULAR evidence based recommendations for the management of hip osteoarthritis: report of a task force of the EULAR Standing Committee for International Clinical Studies Including Therapeutics (ESCISIT). Ann Rheum Dis 2005, 64:669-681.

15. Zhang W, Doherty M, Leeb BF, Alekseeva L, Arden NK, Bijlsma JW, Dinçer F, Dziedzic K, Häuselmann HJ, Herrero-Beaumont G, Kaklamanis $\mathrm{P}$, Lohmander S, Maheu E, Martín-Mola E, Pavelka K, Punzi L, Reiter S, Sautner J, Smolen J, Verbruggen G, Zimmermann-Górska I: EULAR evidence based recommendations for the management of hand osteoarthritis: report of a Task Force of the EULAR Standing Committee for International Clinical Studies Including Therapeutics (ESCISIT). Ann Rheum Dis 2007, 66:377-388.

16. Jordan KM, Arden NK, Doherty M, Bannwarth B, Bijlsma JW, Dieppe $P$, Gunther K, Hauselmann H, Herrero-Beaumont G, Kaklamanis $\mathrm{P}$, Lohmander $\mathrm{S}$, Leeb $\mathrm{B}$, Lequesne $\mathrm{M}$, Mazieres $\mathrm{B}$, Martin-Mola E, Pavelka K, Pendleton A, Punzi L, Serni U, Swoboda B, Verbruggen G, Zimmerman-Gorska I, Dougados M; Standing Committee for International Clinical Studies Including Therapeutic Trials ESCISIT: EULAR Recommendations 2003: an evidence based approach to the management of knee osteoarthritis: Report of a Task Force of the Standing Committee for International Clinical Studies Including Therapeutic Trials
(ESCISIT). Ann Rheum Dis 2003, 62:1145-1155.

17. Pincus $T$, Koch GG, Sokka T, Lefkowith J, Wolfe F, Jordan JM, Luta G, Callahan LF, Wang X, Schwartz T, Abramson SB, Caldwell JR, Harrell RA, Kremer JM, Lautzenheiser RL, Markenson JA, Schnitzer TJ, Weaver A, Cummins P, Wilson A, Morant S, Fort J: A randomized, double-blind, crossover clinical trial of diclofenac plus misoprostol versus acetaminophen in patients with osteoarthritis of the hip or knee. Arthritis Rheum 2001, 44: 1587-1598.

18. Case JP, Baliunas AJ, Block JA: Lack of efficacy of acetaminophen in treating symptomatic knee osteoarthritis: a randomized, double-blind, placebo-controlled comparison trial with diclofenac sodium. Arch Intern Med 2003, 163:169-178.

19. Miceli-Richard C, Le Bars M, Schmidely N, Dougados M: Paracetamol in osteoarthritis of the knee. Ann Rheum Dis 2004, 63: 923-930.

20. Chou R HM, Peterson K, Dana T, Roberts C: Comparative Effectiveness and Safety of Analgesics for Osteoarthritis. Comparative Effectiveness Review No. 4. (Prepared by the Oregon Evidencebased Practice Center under Contract No. 290-02-0024.) Rockville, MD: Agency for Healthcare Research and Quality; 2006.

21. Antman EM, Bennett JS, Daugherty A, Furberg C, Roberts $H$, Taubert KA: Use of nonsteroidal antiinflammatory drugs: an update for clinicians: a scientific statement from the American Heart Association. Circulation 2007, 115:1634-1642.

22. Moskowitz RW, Abramson SB, Berenbaum F, Simon LS, Hochberg M: Coxibs and NSAIDs: is the air any clearer? Perspectives from the OARSI/International COX-2 Study Group Workshop 2007. Osteoarthritis Cartilage 2007, 15:849-856.

23. McGettigan P, Henry D: Cardiovascular risk and inhibition of cyclooxygenase: a systematic review of the observational studies of selective and nonselective inhibitors of cyclooxygenase 2. JAMA 2006, 296:1633-1644.

24. Hernandez-Diaz S, Varas-Lorenzo C, Garcia Rodriguez LA: Nonsteroidal antiinflammatory drugs and the risk of acute myocardial infarction. Basic Clin Pharmacol Toxicol 2006, 98: 266-274.

25. Kearney PM, Baigent C, Godwin J, Halls H, Emberson JR, Patrono C: Do selective cyclo-oxygenase-2 inhibitors and traditional non-steroidal anti-inflammatory drugs increase the risk of atherothrombosis? Meta-analysis of randomised trials. BMJ 2006, 332:1302-1308.

26. Strand V: Are COX-2 inhibitors preferable to non-selective non-steroidal anti-inflammatory drugs in patients with risk of cardiovascular events taking low-dose aspirin? Lancet 2007, 370:2138-2151.

27. Singh G, Graham D, Wang H, Mithal A, Triadafilopoulos G: Concomitant aspirin use reduces the risk of acute myocardial infarction in users of cyclooxygenase- 2 selective and some non-selective nonsteroidal anti-inflammatory drugs. Ann Rheum Dis 2006, 65(suppl II):61.

28. Singh G, Mithal A, Triadafilopoulos G: Both selective COX-2 inhibitors and non-selective NSAIDs increase the risk of acute myocardial infarction in patients with arthritis: selectivity is with the patient, not the drug class. Ann Rheum Dis 2005, 64 (suppl III):85.

29. Silverstein FE, Faich G, Goldstein JL, Simon LS, Pincus T, Whelton A, Makuch R, Eisen G, Agrawal NM, Stenson WF, Burr AM, Zhao WW, Kent JD, Lefkowith JB, Verburg KM, Geis GS: Gastrointestinal toxicity with celecoxib vs nonsteroidal antiinflammatory drugs for osteoarthritis and rheumatoid arthritis: the CLASS study: a randomized controlled trial. Celecoxib Long-term Arthritis Safety Study. JAMA 2000, 284:1247-1255.

30. Farkouh ME, Kirshner H, Harrington RA, Ruland S, Verheugt FW, Schnitzer TJ, Burmester GR, Mysler E, Hochberg MC, Doherty M, Ehrsam E, Gitton X, Krammer G, Mellein B, Gimona A, Matchaba P, Hawkey CJ, Chesebro JH; TARGET Study Group: Comparison of lumiracoxib with naproxen and ibuprofen in the Therapeutic Arthritis Research and Gastrointestinal Event Trial (TARGET), cardiovascular outcomes: randomised controlled trial. Lancet 2004, 364:675-684.

31. Johnson AG, Nguyen TV, Day RO: Do nonsteroidal anti-inflammatory drugs affect blood pressure? A meta-analysis. Ann Intern Med 1994, 121:289-300.

32. Pope JE, Anderson JJ, Felson DT: A meta-analysis of the effects of nonsteroidal anti-inflammatory drugs on blood pressure. 
Arch Intern Med 1993, 153:477-484

33. Sowers JR, White WB, Pitt B, Whelton A, Simon LS, Winer N, Kivitz $A$, van Ingen $H$, Brabant $T$, Fort JG: The effects of cyclooxygenase-2 inhibitors and nonsteroidal anti-inflammatory therapy on 24-hour blood pressure in patients with hypertension, osteoarthritis, and type 2 diabetes mellitus. Arch Intern Med 2005, 165:161-168.

34. Tseng CC, Wolfe MM: Nonsteroidal anti-inflammatory drugs. Med Clin North Am 2000, 84:1329-1344.

35. Garcia Rodriguez LA, Hernandez-Diaz S: Risk of uncomplicated peptic ulcer among users of aspirin and nonaspirin nonsteroidal antiinflammatory drugs. Am J Epidemiol 2004, 159:2331.

36. Hernandez-Diaz S, Rodriguez LA: Association between nonsteroidal anti-inflammatory drugs and upper gastrointestinal tract bleeding/perforation: an overview of epidemiologic studies published in the 1990s. Arch Intern Med 2000, 160: 2093-2099.

37. Mamdani M, Rochon PA, Juurlink DN, Kopp A, Anderson GM, Naglie G, Austin PC, Laupacis A: Observational study of upper gastrointestinal haemorrhage in elderly patients given selective cyclo-oxygenase-2 inhibitors or conventional nonsteroidal anti-inflammatory drugs. BMJ 2002, 325:624.

38. Laine L, Curtis SP, Cryer B, Kaur A, Cannon CP: Assessment of upper gastrointestinal safety of etoricoxib and diclofenac in patients with osteoarthritis and rheumatoid arthritis in the Multinational Etoricoxib and Diclofenac Arthritis Long-term (MEDAL) programme: a randomised comparison. Lancet 2007, 369:465-473.

39. Jones R, Rubin G, Berenbaum F, Scheiman J: Gastrointestinal and cardiovascular risks of nonsteroidal anti-inflammatory drugs. Am J Med 2008, 121:464-474.

40. Moore RA, Derry S, McQuay HJ: Cyclo-oxygenase-2 selective inhibitors and nonsteroidal anti-inflammatory drugs: balancing gastrointestinal and cardiovascular risk. BMC Musculoskelet Disord 2007, 8:73.

41. Rahme E, Nedjar H: Risks and benefits of COX-2 inhibitors vs non-selective NSAIDs: does their cardiovascular risk exceed their gastrointestinal benefit? A retrospective cohort study. Rheumatology (Oxford) 2007, 46:435-438.

42. Palmer BF: Renal complications associated with use of nonsteroidal anti-inflammatory agents. J Investig Med 1995, 43: 516-533.

43. Schlondorff D: Renal complications of nonsteroidal antiinflammatory drugs. Kidney Int 1993, 44:643-653.

44. Weir MR: Renal effects of nonselective NSAIDs and coxibs. Cleve Clin J Med 2002, 69(suppl 1):SI53-SI58.

45. Zhang J, Ding EL, Song Y: Adverse effects of cyclooxygenase 2 inhibitors on renal and arrhythmia events: meta-analysis of randomized trials. JAMA 2006, 296:1619-1632.

46. Garcia Rodriguez LA, Hernandez-Diaz S: Relative risk of upper gastrointestinal complications among users of acetaminophen and nonsteroidal anti-inflammatory drugs. Epidemiology 2001, 12:570-576.

47. Rahme E, Pettitt D, LeLorier J: Determinants and sequelae associated with utilization of acetaminophen versus traditional nonsteroidal antiinflammatory drugs in an elderly population. Arthritis Rheum 2002, 46:3046-3054.

48. Rahme E, Barkun A, Nedjar H, Gaugris S, Watson D: Hospitalizations for upper and lower Gl events associated with traditional NSAIDs and acetaminophen among the elderly in Quebec, Canada. Am J Gastroentero/ 2008, 103:872-882.

49. Curhan GC, Knight EL, Rosner B, Hankinson SE, Stampfer MJ: Lifetime nonnarcotic analgesic use and decline in renal function in women. Arch Intern Med 2004, 164:1519-1524.

50. Fored CM, Ejerblad E, Lindblad P, Fryzek JP, Dickman PW, Signorello LB, Lipworth L, Elinder CG, Blot WJ, McLaughlin JK, Zack $\mathrm{MM}$, Nyrén O: Acetaminophen, aspirin, and chronic renal failure. N Engl J Med 2001, 345:1801-1808.

51. Forman JP, Rimm EB, Curhan GC: Frequency of analgesic use and risk of hypertension among men. Arch Intern Med 2007, 167:394-399.

52. Forman JP, Stampfer MJ, Curhan GC: Non-narcotic analgesic dose and risk of incident hypertension in US women. Hypertension 2005, 46:500-507.

53. Wallace JL: Building a better aspirin: gaseous solutions to a century-old problem. Br J Pharmacol 2007, 152:421-428.
54. Cicala C, lanaro A, Fiorucci S, Calignano A, Bucci M, Gerli R, Santucci L, Wallace JL, Cirino G: NO-naproxen modulates inflammation, nociception and downregulates $\mathrm{T}$ cell response in rat Freund's adjuvant arthritis. $\mathrm{Br} J$ Pharmacol 2000, 130: 1399-1405.

55. Mizoguchi $\mathrm{H}$, Hase S, Tanaka A, Takeuchi K: Lack of small intestinal ulcerogenecity of nitric oxide-releasing indomethacin, NCX-530, in rats. Aliment Pharmacol Ther 2001, 15:257267.

56. Lohmander LS, McKeith D, Svensson O, Malmenas M, Bolin L, Kalla A, Genti G, Szechinski J, Ramos-Remus C: A randomised, placebo controlled, comparative trial of the gastrointestinal safety and efficacy of AZD3582 versus naproxen in osteoarthritis. Ann Rheum Dis 2005, 64:449-456.

57. Davies NM, Roseth AG, Appleyard CB, McKnight W, Del Soldato $P$, Calignano A, Cirino G, Wallace JL: NO-naproxen vs. naproxen: ulcerogenic, analgesic and anti-inflammatory effects. Aliment Pharmacol Ther 1997, 11:69-79.

58. Schnitzer TJ, Kivitz A, Rankin B, Fisher C, Marker $\mathrm{H}$, Frayssinet $\mathrm{H}$, Duquesroix $\mathrm{B}$ : Comparison of naproxcinod to naproxen and placebo: results of a 13-week phase 3 pivotal trial in patients with osteoarthritis of the knee with particular focus on blood pressure effects. Ann Rheum Dis 2008, 67(suppl II):394. 